\title{
Sistem Informasi Geografis Dalam Pemetaan Lahan Gambut di Kabupaten Musi Banyuasin
}

\author{
Alek Wijaya a, Eka Puji Agustini ${ }^{\mathrm{b},}$ Eko Nardo $^{\mathrm{c}}$ \\ ${ }^{a}$ Fakultas Ilmu Komputer, Universitas Bina Darma, alex_wj@binadarma.ac.id \\ ${ }^{\text {b}}$ Fakultas Ilmu Komputer, Universitas Bina Darma, eka@binadarma.ac.id \\ ${ }^{\mathrm{c} F a k u l t a s ~ I l m u ~ K o m p u t e r, ~ U n i v e r s i t a s ~ B i n a ~ D a r m a, e k o @ y a h o o . c o . i d ~}$
}

\begin{abstract}
Conservation of nature is a central issue at this time, this is caused by the increasing number of natural damages that occur because of human ignorance to keep the nature of the world remains a friendly place for our lives. One of the important factor of nature conservation is the sustainability of peatlands which is capable of storing carbon gases that serve to withstand the rate of earth temperature rise. One of the efforts undertaken to maintain the sustainability of peatlands is the availability of the lastest and comprehensive data and information about peatland conditions that can be accessed by stakeholders that related to peatland conditions. For that reason, we need a Geographic Information System that is designed and built using the Classic Life Cycle Model approach and supported by ArcGIS software, UML Model and PHP programming language. Geographic information system provides peatland mapping information such as: location of peatlands, peatland categories, peatlands category that already managed and peatland category not yet managed.
\end{abstract}

Keywords : Geographic Information Systems, Classic Life Cycle Model, ArcGis, Peatland

\begin{abstract}
Abstrak
Kelestarian alam adalah isu yang sangat sentral pada masa ini, hal ini di sebabkan oleh semakin banyaknya kerusakan yang alam yang terjadi dikarenakan ketidakperdulian manusia akan pentingya menjaga agar alam tetap menjadi tempat yang bersahabat untuk kehidupan kita. Salah satu penopang kelestarian alam adalah adanya kelestarian lahan gambut yang mampu menyimpan gas karbon yang berfungsi untuk menahan laju paningkatan suhu bumi. Salah satu upaya yang dilakukan untuk menjaga kelestarian lahan gambut adalah tersedianya data dan informasi tentang kondisi lahan gambut y ang komprehensif dan terbaru y ang bisa diakses oleh piha y ang berkepentngan dengan kondisi lahan gambut. Untuk itulah dibutuhkan suatu Sistem Informasi Geografis yang di desain dan dibangun dengan menggunakan pendekatan Classic Life Cycle Model serta didukung dengan Perangakt lunak ArcGIS, UML Model dan Bahasa pemrograman PHP. Sistem informasi Geografis ini memberikan informasi pemetaan lahan gambut seperti: lokasi lahan gambut, kategori lahan gambut,lahan gambut yng sudah di kelolah dan belum dikelola.
\end{abstract}

Kata Kunci : Sistem informasi geografis, Classic life cycle model, ArcGis, Gambut

(C) 2018 Jurnal RESTI

\section{Pendahuluan}

Keberadaan lahan gambut sangat penting bagi keberlangsungan kehidupan manusia di muka bumi. Hal ini di sebabkan oleh kemampuan lahan gambut untuk menyimpan gas karbon yang berfungsi mencegah emisi lanjutan sehingga kenaikan suhu bumi dapat di hindarkan. Indonesia adalah salah satu negara yang memiliki lahan gambut didunia dengan luas sekitar 21 juta hektar yang tersebar di pulau Sumatera, Kalimantan dan Papua.

Lahan gambut merupakan hasil dekomposisi vegetasi pepohonan yang tidak sempurna, tergenang air dan merupakan jenis tanah yang memiliki kandungan bahan organik yang terbentuk dari sisa tanah tumbuhan yang membusuk karena kondisi lingkungan yang miskin hara dan jenuh air [1]. Keberadaan lahan gambut sangatlah penting sebagai bagian yang terintegrasi dari ekosistem dan keseimbangan alam, Oleh karena itu ketersediaan data dan informasi yang dapat diakses setiap saat mengenai lahan gambut sangatlah diperlukan.

Terkait dengan hal ini, implementasi teknologi dalam pengolahan, penyimpanan dan penyebaran informasi khususnya dalampemetaan lahan gambut sangat penting untuk dipertimbangkan. Hal ini mengingat pesatnya perkembangan teknologi informasi pada saat ini yang telah dimanfaatkan diberbagai bidang dan aktivitas

Diterima Redaksi : 15-03-2018 $\mid$ Selesai Revisi : 03-04-2018 $\mid$ Diterbitkan Online : 16-04-2018 
kehidupan antara lain; bidang perkebunan, pertanian dan gambut, luas gambut, kedalaman, dan lahan gambut pemerintahan. Untuk itulah, tersedianya perangkat lunak yang telah diberi izin oleh pemerintah serta penbaharuan yang disebut dengan Sistem Informasi Geografis atau seberapa besar luas kerusakan lahan gambut di Geographic Information System (GIS) akan sangat Kabupaten Musi Banyuasin menggunakan ArcGIS 10.2 membantu dalam memetakan lokasi dan luas lahan dan website untuk menampilkannya..

gambut secara digital.

Sistem Informasi Geograpis atau Geographical Information System (GIS) merupakan suatu kerangka 2.1. Data Spasial

kerja sistem sistem berbasis komputer yang digunakan untuk mengumpulkan, mengelolah, memanipulasi dan menganalisa dan menyimpan data geografis [2]. Dalam pengertian lain Sistem Informasi Geografis merupakan suatu sistem berbasis komputer yang digunakan untuk menyimpan, memanipulasi menganalis is objek-objek dan fenomena-fenomena dimana lokasi geografis merupakan karateristik yang penting dan kritis untuk dianalisis [3].

Dalam kontek inovasi teknologi, Sistem informasi Geografis sangat penting karena mampu mengintegrasikan sejumlah bidang ilmu dan teknologi menjadi jauh lebih besar dan bermanfaat. GIS memiliki kemampuan untuk mengintegrasikan data dan metode yang biasa digunakan oleh ahli geograpi, dan menawarkan cara baru dalam melakukan pemetaan, pemodelan, manipulasi, analisa data dalam jumlah yang besar didalam sebuah database serta mendistribusikan hasilnya dalam berbagai bentuk visual seperti gambar dan grafik [4].

Kabupaten Musi Banyuasin adalah salah satu daerah di Provinsi Sumatera Selatan yang memiliki lahan gambut yang cukup luas yang tersebar dibeberapa kecamatan dan desa. Permasalahan terkait dengan lahan gambut yang dihadapi kabupaten ini adalah adanya bencana kebakaran lahan gambut karena dipengaruhi oleh faktor alam yang berupa cuaca kering serta faktor manusia yang berupa pembakaran baik sengaja maupun tidak sengaja. Disamping itu data dan informasi terbaru dan komprehensif mengenai lokasi penyebaran lahan gambut, luas kerusakan lahan, kategori lahan gambut, izin pengelolaan lahan dan pemafaatannya oleh masyarakat masih minim dan belum dapat di akses secara optimal.

Hal ini disebabkan masih konvensionalnya pemetaan, pengolahan, penyimpanan data serta pendistribusian informasi terkait lahan gambut oleh Dinas Kehutanan UPTD Pengendalian Kebakaran Hutan dan Lahan Kabupaten Musi Banyuasin

Sehubungan dengan ini, kebutuhan akan suatu perangkat lunak yang mampu menghasilkan informasi yang cepat

dan terbaru mengenai lahan gambut sangat dibutuhkan 2.3. Use Case Diagram agar dapat diakses oleh semua pihak yang berkepentingan akan kelestarian lahan gambut.

Data spasial adalah proses yang menggambarkan objekobjek spasial di dunia nyata sehingga objek-objek yang dirasakan dapat dipresentasikan dalam bentuk notasi yang bisa dimengerti dan digunakan [5].Adapun komponen data spasial seperti Gambar 1.

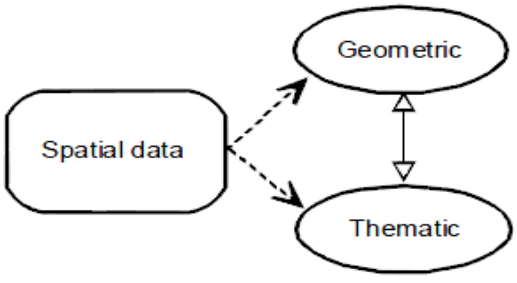

Gambar 1. Komponen data spasial [5]

Data Spasial terdiri dari 2 (Dua) komponen yaitu: (a) Data Geomatic, sebuah model dalam bentuk database memerlukan aspek kategori yang nyata dari database yang dikelola dan dimanipulasi oleh DBMS. (b) Data Thematic, proses untuk mengklasifikasi objek-objek ke dalam kelompok-kelompok sehingga memudahkan untuk membedakan suatu objek dengan objek yang lainnya. Hal ini dimungkinkan karena benda-benda dapat memiliki karakteristik yang sama atau karakteristik yang berbeda.

\subsection{Website}

Website adalah keseluruhan halaman-halaman yang berisikan informasi berupa gambar, tulisan, suara, animasi baik dinamis maupun statis yang terdapat dalam sebuah rangkaian jaringan halamam (link) menggunakan protocol http dan diakses menggunakan web browser [6]. Salah satu perangkat lunak bantu yang bisa digunakan untuk mendesain web adalah Macromedia, yaitu suatu editor HTML, aplikasi desain dan pengembangan web yang menyediakan kode editor dengan fitur standar seperti syntax highlighting, code completion, dan code collapsing serta fitur lebih canggih seperti real-time syntax checking dan code introspection untuk menghasilkan petunjuk kode untuk membantu pengguna dalam menulis kode [7].

Use Case adalah teknik persyaratan fungsional sebuah sistem. Use Case mendeskripsikan interaksi tipikal Dengan didasari hal diatas maka penelitian ini dilakukan antara para pengguna sistem dengan sistem itu sendiri untuk menghasilkan suatu Sistem Informasi Geografis dengan memberikan sebuah narasi tentang bagaimana berbasis web yang menampilkan informasi penyebaran sistem tersebut digunakan [8]. 
Dalam desain use case, pihak yang berinteraksi dengan 2. Gambut adalah material organik yang terbentuk sistem disebut aktor dimana aktor itu sendiri bisa manusia atau pihak lain di luar sistem. Aktor berinteraksi dengan sistem menggunakan satu atau banyak use case sebaliknya sebuah use case juga dapat 3 digunakan oleh beberapa aktor.

\subsection{Peta}

Salah satu bagian penting dalam pembuatan Sistem Informasi Georafis adalah tersedianya peta sebagai media sosial dari karakteristik dipermukaan bumi, peta juga menjadi sumber dari data spasial. secara alami dari sisa-sisa tumbuhan yang terdekomposisi tidak sempurna dan terakumulasi pada rawa.

. Ekosistem Gambut adalah tatanan unsur Gambut yang merupakan satu kesatuan utuh menyeluruh yang saling mempengaruhi dalam membentuk keseimbangan, stabilitas, dan produktivitasnya.

4. Kesatuan Hidrologis Gambut adalah Ekosistem Gambut yang letaknya di antara 2 (dua) sungai, di antara sungai dan laut, dan/atau pada rawa.

Pemahaman tentang peta adalah representasi simbolic Perlindungan dan Pengelolaan Ekosistem Gambut dari suatu tempat yang di gambarkan sebagai suatu sebagaimana dimaksud dalam Pasal 2 ayat (2) meliputi: permukaan datar yang menberikan informasi tentang a. perencanaan; b. pemanfaatan; c. pengendalian; d. suatu negara, luas wilayah, jarak antar wilayah dan pemeliharaan; e. pengawasan; dan f. sanksi karakteristik dari suatu tempat yang di visualkan dengan administratif. Dengan peraturan ini diharapkan skala[9].

kerusakan lahan gambut dapat dicegah.

\subsection{ArcGis}

\section{Metodologi Penelitian}

Dalam proses pengembangan perangkat lunak sistem Metode pada penelitian ini menggunakan metode informasi geografis, ada beberapa hal yang perlu deskriptif. Penelitian deskriptif merupakan penelitian diperhatikan yaitu pengaturan unit peta yang kita buat, yang dimaksudkan untuk mengumpulkan informasi penentuan skala tampilan, penentuan sistem koordinat mengenai status suatu gejala yang ada, yaitu keadaan serta pengaturan grid koordinat pada layout. Untuk itu gejala menurut apa adanya pada saat penelitian diperlukan alat bantu berupa perangkat lunak yang dapat dilakukan[12].

mengakomodasi beberapa hal-hal tersebut yakni menggunakan perangkat lunak yang disebut ArcGis.

Tujuan penelitian deskriptif adalah untuk membuat penggambaran yang jelas secara sistematis, faktual, dan

ArcGis adalah sebuah solusi perangkat lunak aplikasi akurat mengenai fakta-fakta dan sifat-sifat populasi atau sistem informasi geografis yang integral serta terdapat daerah tertentu.

beberapa aplikasi sistem informasi geografis yang memiliki fungsi berbeda. Di antaranya adalah ArcView, ArcMap, ArcCatalog dan ArcReader [10]. ArcGIS dikembangkan oleh ESRI (Environment Science \& Research Institue) yang merupakan kompilasi fungsifungsi dari berbagai macam software GIS yakni GIS desktop, server, dan GIS berbasis web.

\subsection{Dasar hukum pengelolaan lahan gambut}

Dalam rangka untuk membangkitkan kesadaran akan pentingya kelestarian lahan gambut dan dengan mempertimbangkan bahwa lahan gambut adalah lahan yang sangat penting dan rawan terjadi kerusakan.

Pemerintah telah membuat Peraturan Pemerintah (PP) No.71 Tahun 2014 tentang Perlindungan dan Pengelolaan Ekosistem Gambut antara lain[11]:

\section{a. Pasal 1}

1. Perlindungan dan Pengelolaan Ekosistem Gambut adalah upaya sistematis dan terpadu yang dilakukan untuk melestarikan fungsi Ekosistem Gambut dan mencegah terjadinya kerusakan Ekosistem Gambut yang meliputi perencanaan, pemanfaatan, pengendalian, pemeliharaan, pengawasan, dan penegakan hukum.

Dalam penelitian ini metode pengembangan perangkat lunak yang digunakan adalah pendekatan pemodelan siklus hidup klasik (Classic life cycle model). Model proses ini menitik beratkan pada pendekatan terhadap perkembangan perangkat lunak yang sistematik dan sekuensial dimulai dari tingkat dan kemajuan sistem pada analisis, desain, kode, pengujian, dan pemeliharaan[13]. Adapun model siklus hidup klasik tersebut dapat di lihat pada Gambar 2.

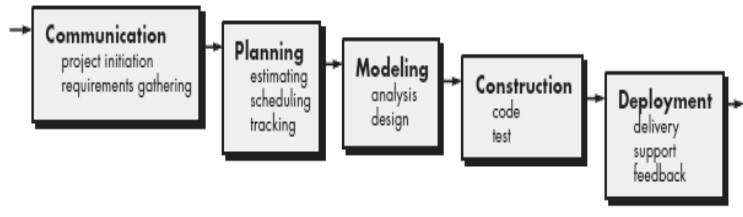

Gambar 2. Classic Lifecycle Model [13]

Berikut ini adalah penjelasannya tentang model siklus hidup klasik yaitu :

\section{Komunikasi}

Pada tahap ini dilakukan komunikasi dengan pihak yang akan menggunakan atau yang berkepentingan dengan sistem informasi yang akan dibuat, dalam hal ini diskusi dan komunikasi dilakukan dengan pegawai pada Dinas 
Kehutanan UPTD Pengendalian Kebakaran Hutan dan persyaratan sistem atau user requirement dan system Lahan Kabupaten Musi Banyuasin. Komunikasi di requirement sebagai berikut:

fokuskan pada analisis kebutuhan perangkat lunak, pemahaman tentang proses bisnis dan fungsi yang terkait dengan perangkat lunak serta antar muka (user interface) yang sesuai dengan keinginan pengguna.

\section{Perencanaan}

Fokus pada tahap perencanaan ini adalah menetapkan rencana pengembangan dari perangkat lunak sistem informasi geografis lahan gambut. Kegiatan yang dilakukan antara lain: penentuan tugas-tugas teknis yang harus dipenuhi, analisa resiko yang mungkin akan dihadapi, penentuan sumber daya yang dibutuhkan serta jadwal kerja.

\section{Pemodelan}

Tabe.1. Tabel Kebutuhan Pengguna Terhadap Sistem

\begin{tabular}{lll}
\hline No & $\begin{array}{l}\text { Bagian/ } \\
\text { Unit Kerja }\end{array}$ & Kebutuhan Sistem \\
\hline 1 & Administrator & $\begin{array}{l}\text { Adanya proses pembuatan peta } \\
\text { dengan argis } \\
\text { Adanya pengunggahandata peta } \\
\text { pada argis Online } \\
\text { Adanya Proses peletakan script web } \\
\text { gis Online } \\
\text { Adanya informasi mengenai lahan } \\
\text { gambut melalui aplikasi GIS }\end{array}$ \\
\hline
\end{tabular}

\subsection{Pemodelan}

Tahapan ini menghasilkan suatu model dengan mendeskripsikan kebutuhan perangkat lunak (software) Tahapan ini menghasilkan suatu model yang dan fungsi dari perangkat lunak untuk menggambarkan memungkinkan pengembang dan pengguna memahami proses bisnis yang terjadi pada suatu organisasi, Alat lebih lanjut mengenai kebutuhan perangkat lunak dan bantu yang digunakan untuk pemodelan ini adalah perancangan-perancangan untuk memenuhi kebutuhan diagram-diagram Unified Modeling Language (UML) tersebut. Desain perangkat lunak adalah proses berfokus yang merupakan bahasa pemodelan berorientasi objek. pada empat atribut sebuah program yakni struktur data, Adapun bentuk pemodelan yang dibuat adalah sebagai arsitektur perangkat lunak, representasi antarmuka, dan berikut : algoritma.

\section{Konstruksi}

\section{a. Use Case Diagram}

Diagram Use case digunakan untuk menjelaskan bisnis

Tahapan kontruksi merupakan proses pembuatan kode. Program. Proses pengkodean merupakan proses menterjemahkan desain menggunakan bahasa yang dimengerti komputer yakni menggunakan bahasa pemrograman. Hasil dari pengkodean ini adalah sebuah Sistem informasi geografis lahan gambut.

\section{Penyebaran}

Pada tahapan ini, perangkat lunak di uji cobakan kepada pengguna untuk memperoleh masukan sebagai dasar dalam melakukan evaluasi dan perbaikan.

\section{Hasil dan Pembahasan}

Hasil penelitian ini adalah sebuah Aplikasi Sistem Informasi Geografis berbasis web yang menampilkan data dan informasi penyebaran gambut, luas lahan gambut, kedalaman, lahan gambut yang telah diberi izin oleh pemerintah serta penbaharuan seberapa besar luas kerusakan lahan gambut di Kabupaten Musi Banyuasin. Secara detail pembahasannya adalah sebagai berikut:

\subsection{Komunikasi}

Pada tahapan ini dilakukan komunikasi yang intensif antara peneliti dan calon pengguna dari perangkat lunak dalam upaya untuk mendapatkan kesamaan pandangan dan menggali kebutuhan pengguna terkait dengan sistem informasi GIS ini. Adapun hasil Proses pencarian kebutuhan ini didapatkan sesamaan pandangan yang di tuangkan dalam bentuk persyaratan pengguna dan proses dan tanggapan perangkat lunak apabila ada aktivitas yang dilakukan aktor dalam sistem. Dalam hal ini terdapat 2 (Dua) aktor yakni Administrator dan Masyarakat. Aktor Administrator melakukan proses pembuatan Arc katalog peta, selanjutnya menentukan georefrencing, aktivitas berikutnya adalah memasukkan data spasial peta, dibuat, maka case dilanjutkan dengan mengunggah peta, mengisi database, mengunggah peta ke arcgis dan membagikan peta gis ke website.

Sedangkan aktor masyarakat melakukan aktivitas seperti membuka website untuk mendapatkan informasi mengenai lahan gambut. Secara detail diagram use case dapat dilihat pada Gambar 3.

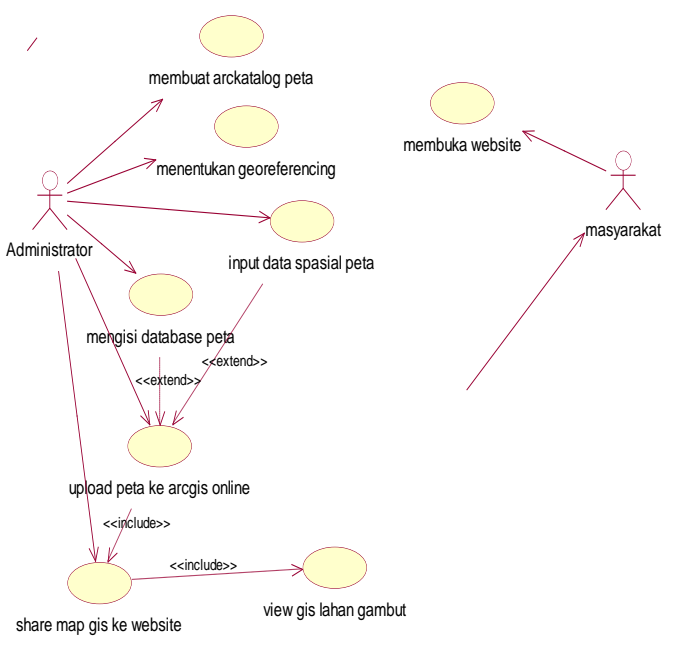

Gambar 3. Use case diagram Sistem informsi geografis lahan gambut 
Berikut adalah detail case yang dilakukan oleh aktor lunak Sistem Informasi Geografis lahan gambut yang Administrator dalam webgis ini yaitu : secara detail dapat di jelaskan sebagai berikut:

1. Membuat arcCatalog peta yaitu proses pembuatan area kerja dan menentukan konsep dari peta yang akan dibangun sepeti menambahkan gambar peta dan menentukan jenis shapefile yang akan digunakan.

\section{a. Halaman Utama}

Pada halaman utama berisikan halaman pembuka Sistem Informasi Geografis Pemetaan Lahan Gambut Sumatera Selatan. Pengunjung dapat memilih menu yang ada pada halaman utama sesuai dengan apa yang diketahui

2. Menentukan georeferencing yaitu proses penandaan point area kerja dari map.

3. Menentukan data spasial peta yaitu proses polygon wilayah kecamatan dan lahan gambut diwilayah Sumatera Selatan.

4. Mengisidatabase peta yaitu proses pendataan peta lahan gambut kedalam data database.

5. Unggah peta ke arcgis online yaitu pengunggahan data spacial kedalam acrgis online. Setelah data terunggah, peta arcgis online tersebut di subscript kedalam layout website. Untuk dapat di akses oleh masyarakat dan stakeholders lain.

\section{b. Activity Diagram}

Activity diagram adalah diagram yang menggabungkan aliran kerja (workflow) atau aktivitas user terhadap sistem dalam mengelola data peta gis kedalam webgis. Secara terperinci activity diagram sistem informasi lahan gambut dapat dilihat pada gambar 4.

Dari activity diagram diuraikan tahapan-tahapan dalam pengguna mengenai lahan gambut,.seperti dapat dilihat pada Gambar 5.

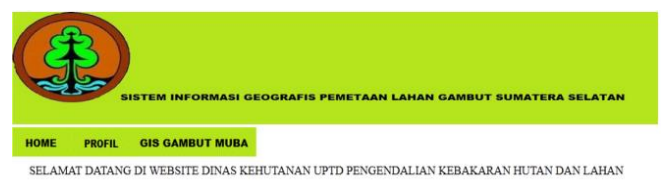

Gambar 5..Halaman utama web gis mengelola webgis sebagai berikut: Pertama-tama b. Halaman Gis Gambut Administrator membuka arcmap terlebih dahulu, setelah Pada halaman Gis Gambut Kabupaten Muba berisikan itu mengisi arccatalog peta, menentukan georefrencing layout peta lahan gambut setiap kecamatan di Kabupaten peta, mamasukkan data spasial dan mengisi database. Musi Banyuasin yang berisi informasi tentang luas lahan Tahapan selanjutnya adalah mengunggah hasil gambut, luas kerusakan dan pembaharuan. Gambar 6 . pengolahan peta kedalam arcgis online. Tahapan akhir adalah mengunggah hasil scrip yang di unggah untuk diletakkan ke dalam website.

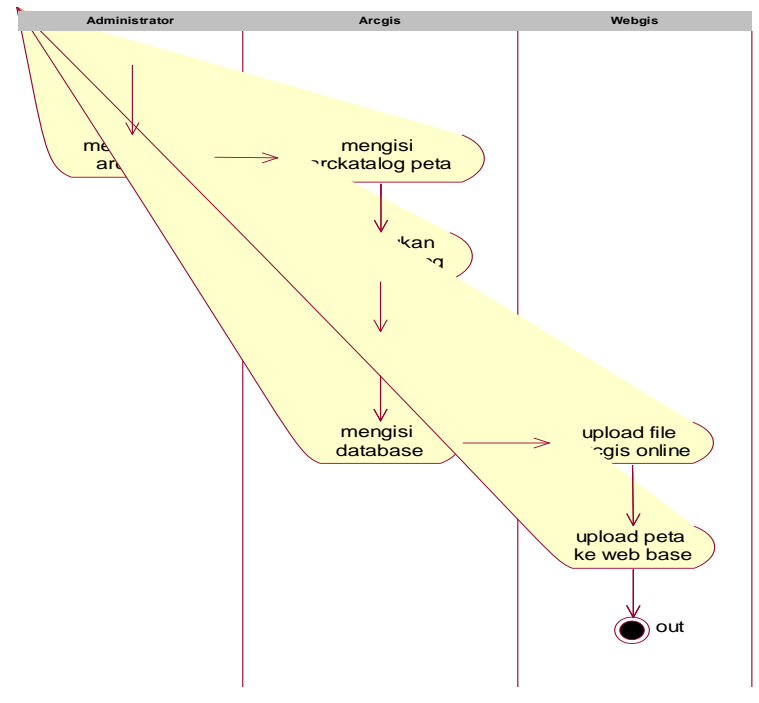

Gambar 4. Activity diagram

Setelah melalui beberapa tahapan dan proses maka didapatlah hasil akhir dari penelitian ini yaitu perangkat

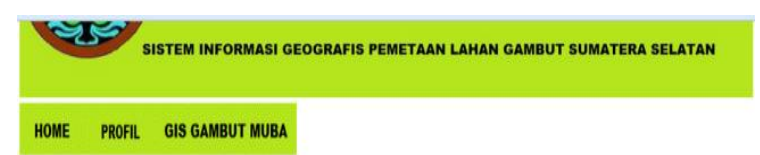

ArcGIS - Lahan Gambut Kabupaten Muba Modify Map \& Sign In

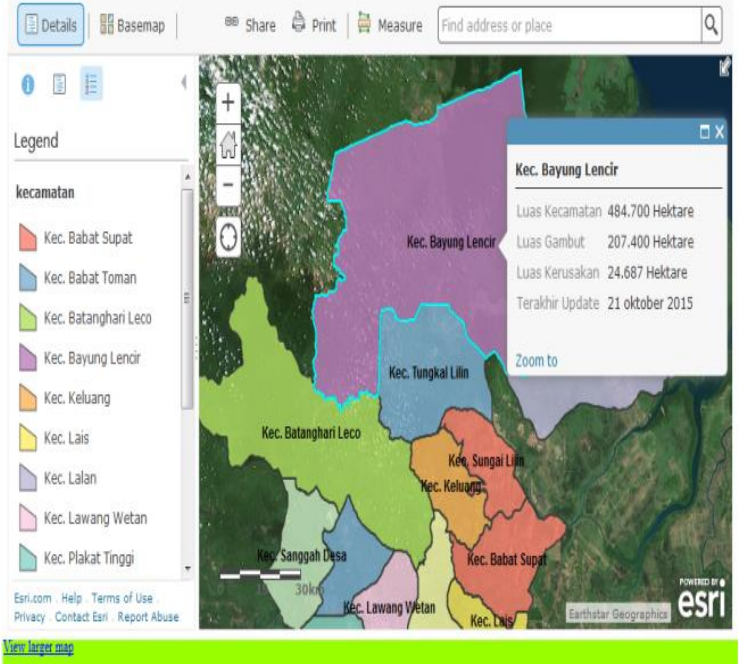

Gambar 6. Halaman Peta Gis lahan gambut perkecamatan 
c. Halaman Gis Gambut Kategori Gambut

Pada halaman ini, terdapat informasi tentang gambut berdasarkan kategori lahan gambut. Layout peta lahan gambut di Kabupaten Musi Banyuasin dapat diakses pengunjung untuk dapat melihat informasi detail mengenai lahan gambut seperti luas lahan dan kedalam gambut. Pengunjung dapat mencentang gambut dan mengklik wilayah berwarna hitam, seperti terlihat pada Gambar 7.

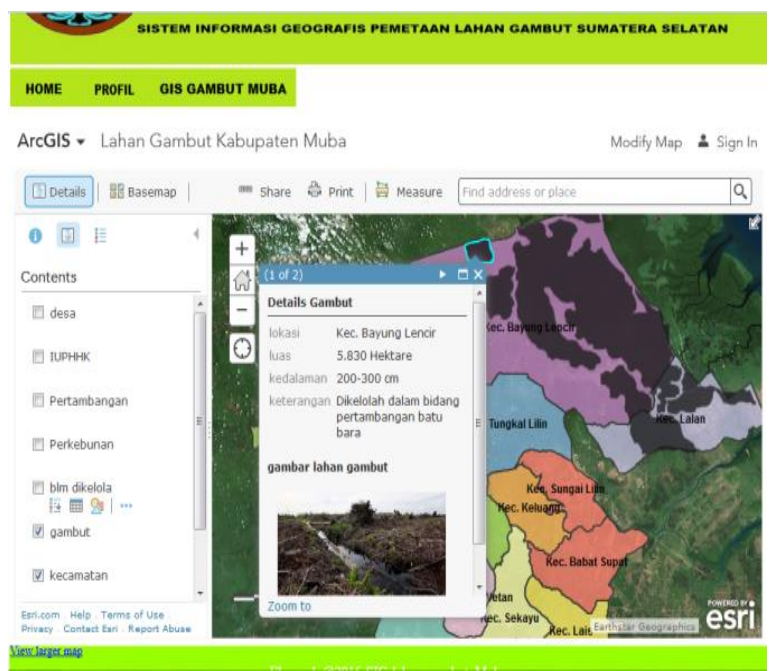

Gambar 7. Halaman Gis lahan gambut perkategori

d. Halaman Gis Gambut Muba Kategori Belum dikelola

Pada Gambar 8 adalah halaman gis gambut kategori belum di kelola. Pada halaman ini berisikan layout peta gambut yang belum di kelola oleh pihak manapun. Pengunjung web dapat melihat informasi detail mengenai lahan gambut yang belum di kelola dengan mencentang belum dikelola pada contents dan mengklik wilayah berwarna coklat.

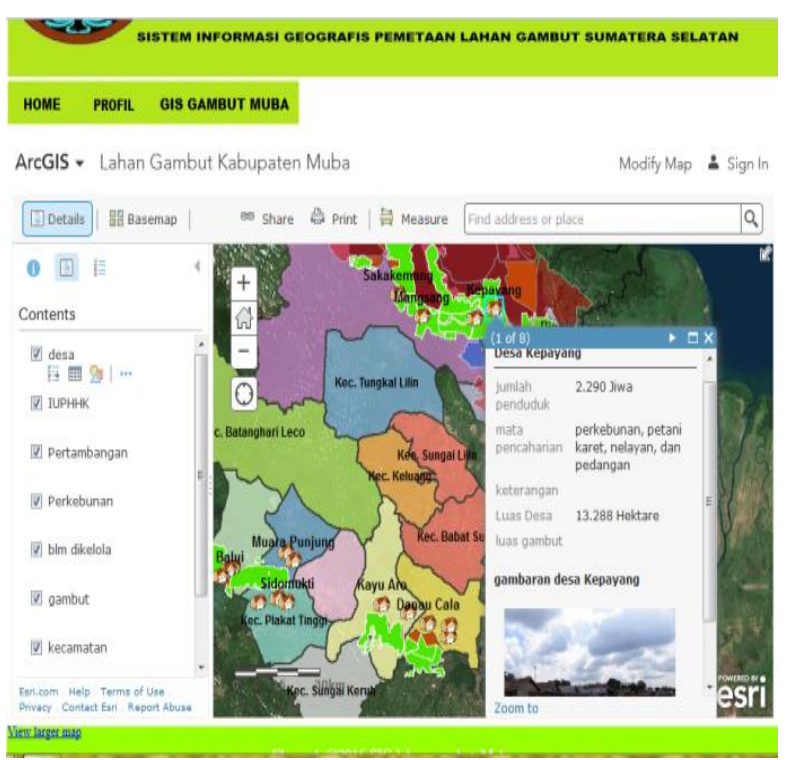

Gambar 8. Halamn Gis lahan gambut yang belum di kelolah
E. Lahan gambut yang di kelola perusahaan

Halaman berikutnya adalah informasi mengenai lahan gambut yang telah mendapat izin untuk dilakukan pengelolaan, lihatGambar 9.

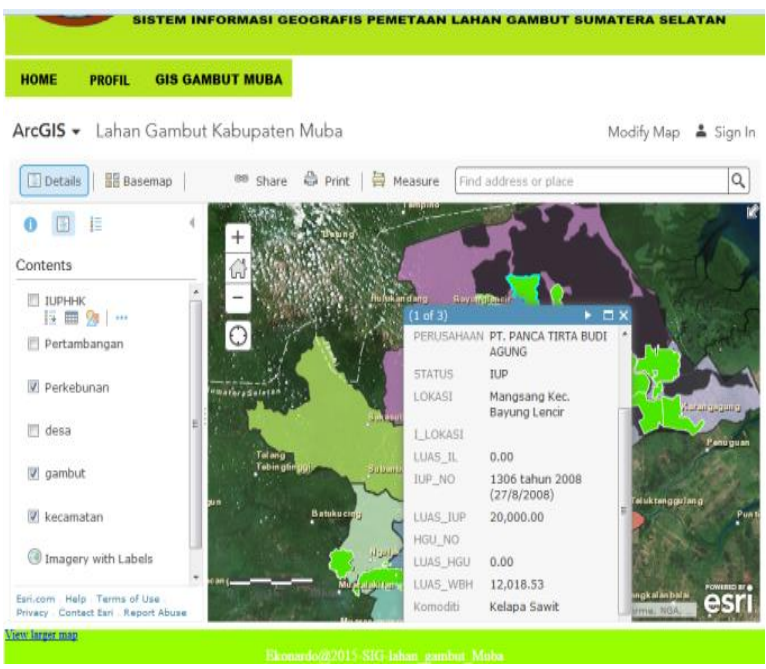

Gambar 9. Halaman Gis lahan gambut yang telah dikelolah.

\section{F. Lahan gambut kategori desa}

Pada Gambar 10 adalah layout yang menginformasikah desa yang berada di derah yang memiliki lahan gambut. Informasi yang dapat diperoleh antara lain: luas desa, luas lahan gambut, jumlah penduduk dan mata pencarian penduduk.

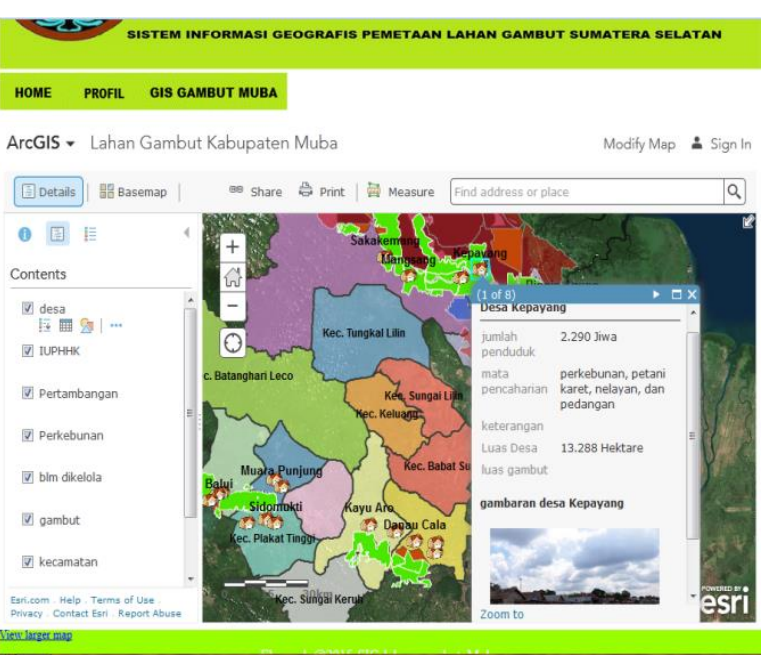

Gambar 10. Halaman Peta Gis lahan gambut per desa

\section{Kesimpulan}

\subsection{Kesimpulan}

Dari penelitian yang telah dilakukan ini dapat disimpulkan hal-hal sebagai berikut:

1. Sistem Informasi Geografis ini memiliki fasilitas untuk mengumpulkan, mengolah, memperbaharui dan menyimpan data lahan gambut dalam database, 
disajikan dalam bentuk visual sehingga para pihak [8] Martin,F,2005. UML Distilled,Edisi 3, Andi, Yogjakarta atau masyarakat yang berkepentingan dapat lebih [9] National Geografic,2017. Map, [Online] mudah mengakses informasi yang terbaru tentang Availabel kondisi lahan gambut.

https://www.nationalgeographic.org/ency clopedia/map/

2. Sistem Informasi Geografis Pemetaan Lahan (Accesed 15 Desember 2017)

Gambut terdiri dari halaman-halaman web yang [10] Awaluddin, N 2010. Geopraphical Information System terdiri dari antara lain: halaman web lahan gambut with ArcGis 9.x edisi 1, Andi, Yogy akarta.

perkecamatan, halaman web lahan gambut perdesa, [11] Lembaran Negara Republik Indonesia,2014,Peraturan halaman web per kategori gambut, halaman web Pemerintah Republik Indonesia No.71 Tahun 2014. [Online] lahan gambut yang belum dikelolah, halaman web Available lahan gambut yang sudah di kelolah perusahaan.

http://www.kemendagri.go.id/media/documents/2014/11/13/p

3. Dengan adannya Sistem Informasi Geografis ini /p/pp_no.71-2014.pdf (Accessed 18 Januari 2018)

diharapkan dapat mempermudah Unit Pelaksanaan [12] Arikunto,2002. Metodelogi penelitian suatu pendekan Teknis Dinas Pengendalian Kebakaran Hutan dan

Lahan mengambil langkah-langkah strategis dalam [13] Roger S. P, 2002. Rekayasa Perangkat Lunak Pendekatan upaya menyelamatkan keberadaan lahan gambut. Praktisi, Andi, Yogy akarta.

\subsection{Saran}

Adapun saran untuk penelitian tentang SistemInformasi Geogafis ini adalah :

1. Perlu dilakukan pelatihan kepada para petugas yang mengelolah sistem, agar Sistem Informasi Geografis dapat berfungsidengan baik dan selalu dapat diakses oleh pengguna

2. Untuk menjaga keberlangsungan sistem dan mengantisipasi hal yang tidak diinginkan maka sistem ini harus terus menerus di pelihara dan di lakukan penggandaan sistem (Back up system)

3. Penulis menyarankan agar Penelitian berikutnya untuk dapat merekayas a perangkat lunak GIS dengan mengintegrasikan Sistem Informasi Geografis untuk beberapa Provinsi atau Kabupaten kota yang memiliki lahan gambut.

\section{Daftar Rujukan}

[1] Jurnal Bumi, 2017. Lahan Gambut [Online] (Update 2 Maret 2018) Available at:https://jurnalbumi.com/lahangambut/_(accessed 19 februari 2018)

[2] Environmental System Research Institute, 2017. What is GIS (A framework to organize, communicate, and understand the science of our world).[Online] Available at: https://www.esri.com/en-us/what-is-gis/overview (Accessed 12 Februari 2018)

[3] Eddy,P, 2009. Sistem Informasi Geografis konsep-konsep dasar (perspektif geodesi \& Geomatika, Informatika, Bandung. [4]Kennet,E.F,M argaret,L, 2015. Geographic Information System as an Integrating Technology: Context,,Concepts, and Definition [Online] Available at: https://www.colorado.edu/geography/gcraft/notes/intro/intro. html_(Accessed 15 Januari 2018)

[5] Abdul,R,A.Pilouk,M, 2008. Spatial Data Modelling for 3D GIS, Springer: New york

[6] Zanzad, FH. 2005. Teknik Pengolahan Video dengan Windows Movie Maker. Indah Surabaya

[7] Arief M R. 2011. Pemrograman Web Dinamis menggunakan PHP dan MySQL,C.V ANDI OFFSET.

Yogy akarta 